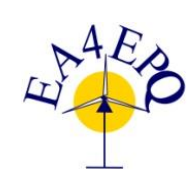

International Conference on Renewable Energies and Power Quality (ICREPQ'16)

Madrid (Spain), $4^{\text {th }}$ to $6^{\text {th }}$ May, 2016

Renewable Energy and Power Quality. Fournal (RE\&PQJ)

ISSN 2172-038 X, No.14 May 2016

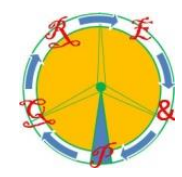

\title{
Different LC power filter topologies - effectiveness of reducing voltage distortion
}

\author{
Chamberlin Stéphane Azebaze Mboving ${ }^{1}$, Zbigniew Hanzelka, Andrzej Mondzik, \\ AGH University of Science and Technology
}

Al. Mickiewicza 30, 30-059 Krakow

(+48) 12 617-28-01

stephane@agh.edu.pl

\begin{abstract}
This Paper aims to present a comparative study of different passive filter configurations. Five topologies of passive RLC filters for the purpose of the mitigation of harmonics voltage distortion are considered. Basis for evaluating the effectiveness of different filter topologies are simulation and laboratory studies.
\end{abstract}

Keywords - passive filters, voltage distortion, current distortion, reactive power, power losses

\section{Introduction}

The parallel connected LC filter is one of the most popular solutions used to compensate the load reactive power and to reduce the current harmonics flowing through the supply network [1].

There exist several topologies of such filters varying by the components number, the reduction level of voltage distortion at PCC, the immunity on detuning phenomena due to the change of capacitance and inductance of the used capacitors and reactors, the power losses, the filtering band etc. Each of the highlighted features has influence on filter designing and its exploitation cost. Therefore it is important to know the advantages and disadvantages of each topology while deciding on its choice and also in optimal decision taking in terms of technical and economical point of view.

The purpose of this paper is to present a comparative analysis of different circuit topologies used to reduce the voltage distortion at the connection point of non-linear load. This paper is mainly focused on filter power losses and the reduction level of current and voltage distortion at the installation site of filter.

The non-linear load used in this studies is the laboratory model of adjustable speed drive (ASD) with DC drive connected to the DC side of a thyristor bridge. The simulation studies have been done in the environment of MATLAB/SIMULINK [2]. The results of simulation studies for selected filter configuration are verified with laboratory model.

\section{Simulated power system}

Five different filter topologies (from 1 to 5) are tested in three phase power system and because of its symmetry the analysis is done only in one phase (Fig. 1).

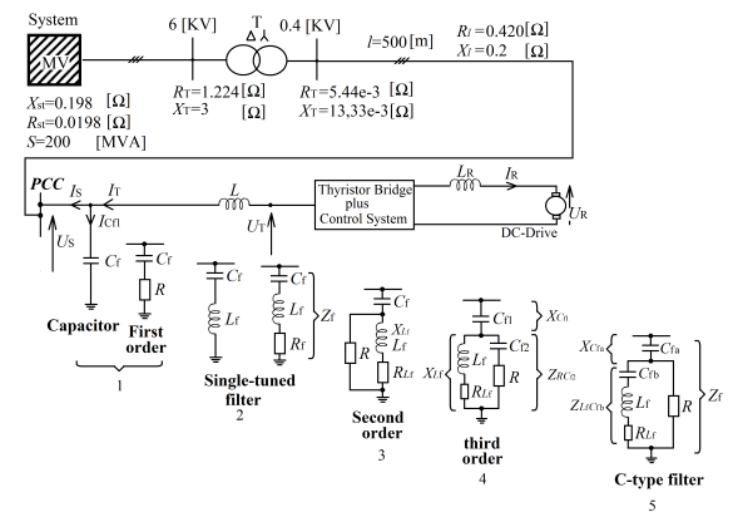

Fig. 1. Simulated power system and the analysed filter configurations (1-5)

\section{A. Power system description}

It consists of three-phase electrical power source with transformer $(T)$, line $(l)$ feeding phase controlled rectifier thyristor bridge with DC drive at its DC side and input reactor $(L)$ at $\mathrm{AC}$ side (Fig. 1). Between the reactor $(L)$ and the PCC, different filter topologies are connected and analyzed. The rest of symbols used in the paper are explained in Fig. 1.

\section{B. Simulation assumptions}

The filters (apart the topology 1) are tuned to the frequency lower than the frequencies of the $5^{\text {th }}$ harmonic $\left(4.85^{\text {th }}\right)$ but the analysis is more focused on the reduction of fifth harmonic amplitude in the system. For each configuration, the resistances of the capacitors are neglected, the reactors are air-core and their resistance are computed by the quality factor $(q)$, the reactive power (fundamental harmonic) used for the system compensation is identical $\left(Q_{\mathrm{f}}=-21725\right.$ Var), the firing angle generated by the control system $\left(\theta=57^{\circ}\right)$ is constant as well as the DC drive speed $(\omega=1500 \mathrm{rpm})$. The data and characteristics of current and voltage at the AC side of thyristor bridge are presented at the steady state.

\section{Parameters computation}

The parameters of each topology are calculated by the expressions of Tab I. The parameters of the $2^{\text {nd }}$ order and single-tuned filter are almost the same. The $2^{\text {nd }}$ order filter was designed by connecting to the single-tuned 
filter the damping resistance $R$ (in parallel with the reactor $\left.L_{\mathrm{f}}\right)$. The resistance of single-tuned filter $\left(R_{\mathrm{f}}\right)$ is considered as a part of the reactor of $2^{\text {nd }}$ order filter. The series and parallel resonance of the $3^{\text {rd }}$ order filter are respectively represented by $n$ and $n_{\mathrm{p}} \cdot \omega_{(1)}$ - angular frequency of the fundamental harmonic, q' - quality factor of single-tuned filter.

Table I. - Expressions used to compute the parameters of each topology

\begin{tabular}{|c|c|}
\hline Capacitors & $C_{\mathrm{f}}=\frac{Q_{\mathrm{f}}}{\omega_{(1)} U_{\mathrm{f}}^{2}}$ \\
\hline Single-tuned filter & $\begin{array}{l}C_{\mathrm{f}}=\frac{n^{2}-1}{n^{2}} \frac{Q_{\mathrm{f}}}{\omega_{(1)} U_{\mathrm{f}}^{2}} \\
R_{\mathrm{f}}=\frac{1}{\mathrm{q}^{\prime}} \sqrt{\frac{L_{\mathrm{f}}}{C_{\mathrm{f}}}} \\
L_{\mathrm{f}}=\frac{1}{\left(n^{2}-1\right)} \frac{U_{\mathrm{f}}^{2}}{\omega_{(1)} Q_{\mathrm{f}}}\end{array}$ \\
\hline $2^{\text {nd }}$ order damped filter & $\begin{array}{l}{ }_{L f}=R_{\mathrm{f}} \\
\text { (See single-tuned paramete }\end{array}$ \\
\hline $3^{\text {rd }}$ order damped filter & $\begin{array}{l}C_{\mathrm{f} 1}=\frac{n_{\mathrm{p}}^{2}\left(1-n^{2}\right)}{n^{2} \omega_{(1)}\left(n_{\mathrm{p}}^{2}-1\right)} \frac{Q}{U_{\mathrm{f}}^{2}} \\
C_{\mathrm{f} 2}=\frac{1}{n_{\mathrm{p}}^{2} \omega_{(1)}^{2} L_{\mathrm{f}}} \\
L_{\mathrm{f}}=\frac{n_{\mathrm{p}}^{2}-n^{2}}{n_{\mathrm{p}}^{2} n^{2} \omega_{(1)}^{2} C_{\mathrm{f} 1}} \\
R_{L \mathrm{f}}=\frac{\omega_{(1)} L_{\mathrm{f}}}{q} \\
n_{\mathrm{p}}>n^{2}\end{array}$ \\
\hline C-type filter & $\begin{array}{l}L_{\mathrm{f}}=\frac{1}{\omega_{(1)}^{2} C_{\mathrm{fb}}} \\
C_{\mathrm{fa}}=\frac{Q_{\mathrm{f}}}{\omega_{(1)} U_{\mathrm{f}}^{2}} \\
C_{\mathrm{fb}}=\left(n^{2}-1\right) C_{\mathrm{fa}}\end{array}$ \\
\hline
\end{tabular}

Table II. Parameters of first order filter

\begin{tabular}{|c|c|c|c|c|c|}
\hline $\begin{array}{c}Q_{\mathrm{f}} \\
{[\mathrm{Var}]}\end{array}$ & $\begin{array}{c}C_{\mathrm{f}} \\
{[\mu \mathrm{F}]}\end{array}$ & $\begin{array}{c}X_{\mathrm{Cf}(1)} \\
{[\Omega]}\end{array}$ & $\begin{array}{c}X_{\mathrm{CF}(5)} \\
{[\Omega]}\end{array}$ & $\begin{array}{c}X_{\mathrm{Cf}(7)} \\
{[\Omega]}\end{array}$ & $\begin{array}{c}\mathrm{R}_{\mathrm{f}} \\
{[\Omega]}\end{array}$ \\
\hline-2172.5 & 130.72 & 24.35 & 4.87 & 3.48 & 0.25 \\
\hline
\end{tabular}

Table III. Parameters of single-tuned filter

\begin{tabular}{|c|c|c|c|c|c|c|}
\hline $\mathrm{f}[\mathrm{Hz}]$ & $n$ & $C_{\mathrm{f}}[\mu \mathrm{F}]$ & $\begin{array}{c}L_{\mathrm{f}} \\
{[\mathrm{mH}]}\end{array}$ & $\begin{array}{c}Z_{\mathrm{f}(5)} \\
{[\Omega]}\end{array}$ & $\begin{array}{c}Z_{\mathrm{f}(1)} \\
{[\Omega]}\end{array}$ & $\begin{array}{c}Q_{\mathrm{f}} \\
{[V a r]}\end{array}$ \\
\hline 205 & 4.1 & 122.95 & 4.9 & 2.52 & & \\
\hline 235 & 4.70 & 124.81 & 3.7 & 0.67 & \multirow{2}{*}{24.35} & -2172.5 \\
\hline 245.5 & 4.85 & 125.17 & 3.4 & 0.32 & & \\
\hline 250 & 5 & 125.49 & 3.2 & 0.00 & & \\
\hline
\end{tabular}

The parameters of $1^{\text {st }}, 2^{\text {nd }}$ and $3^{\text {rd }}$ order filter are respectively presented in Tab II, V, and VI are presented in Tab II. The single-tuned filter parameters are computed for different values of detuning frequency (Tab III.).
There are different opinions on how should be detuned the single-branch filter [3]. In [4] it is suggested that detuning should be in the range of 3 to $15 \%$ below the frequency of harmonic to be eliminated. The order $(n)$ of detuning frequencies presented in Tab III were randomly chosen. The C-type filter parameters are shown in Tab VII. The resistance of single-tuned filter computed from the quality factor is presented in Tab IV.

Table IV. Parameters of single-tuned filter

\begin{tabular}{|c|c|c|c|c|c|c|c|}
\hline $\mathrm{q}^{\prime}$ & $\begin{array}{c}R_{\mathrm{f}} \\
{[\mathrm{m} \Omega]}\end{array}$ & $\begin{array}{c}Z_{\mathrm{f}(5)} \\
\mathrm{m}[\Omega]\end{array}$ & $\begin{array}{l}Z_{\mathrm{f}(1)} \\
{[\Omega]}\end{array}$ & $\begin{array}{c}C_{\mathrm{f}} \\
{[\mu \mathrm{F}]}\end{array}$ & $\begin{array}{c}L_{\mathrm{f}} \\
{[\mathrm{mH}]}\end{array}$ & $Q_{\mathrm{f}}[\mathrm{Var}]$ & $n$ \\
\hline Inf & 0 & 319.5 & 24.3498 & \multirow{4}{*}{125.17} & \multirow{4}{*}{3.4} & \multirow{4}{*}{-2172.5} & \multirow{4}{*}{4.85} \\
\hline 70 & 74.9 & 328.1 & 24.3499 & & & & \\
\hline 21 & 250 & 405.5 & 24.3511 & & & & \\
\hline 10 & 524.3 & 614 & 24.3555 & & & & \\
\hline
\end{tabular}

Table V. Parameters of $2^{\text {nd }}$ order filter $\left(Q_{\mathrm{f}}=-2172.5\right.$ Var $)$

\begin{tabular}{|c|c|c|c|c|c|c|}
\hline$R[\Omega]$ & $Z_{\mathrm{f}(5)}[\Omega]$ & $Z_{\mathrm{f}(1)}[\Omega]$ & $\begin{array}{c}R_{\mathrm{f}} \\
{[\mathrm{m} \Omega]}\end{array}$ & $\begin{array}{c}C_{\mathrm{f}} \\
{[\mu \mathrm{F}]}\end{array}$ & $\begin{array}{c}L_{\mathrm{f}} \\
{[\mathrm{mH}]}\end{array}$ & $n$ \\
\hline- & 0.3281 & 24.35 & & & & \\
\cline { 1 - 2 } & 0.6150 & 24.353 & \multirow{2}{*}{74.9} & \multirow{2}{*}{125.17} & 3.4 & 4.85 \\
\hline 18 & 1.5551 & 24.363 & & & & \\
\hline 8 & 2.8997 & 24.389 & & & & \\
\hline
\end{tabular}

Table VI. Parameters of $3^{\text {rd }}$ order filter $\left(Q_{\mathrm{f}}=-2172.5\right.$ Var and $\left.n=4.85\right)$

\begin{tabular}{|c|c|c|c|c|c|c|c|}
\hline $\begin{array}{c}R \\
{[\mathrm{~m} \Omega]} \\
\end{array}$ & $\begin{array}{c}Z_{\mathrm{f}(5)} \\
{[\mathrm{m} \Omega]}\end{array}$ & $\begin{array}{c}Z_{\mathrm{f}(1)} \\
{[\mathrm{m} \Omega]}\end{array}$ & $\begin{array}{c}R_{\mathrm{Lf}} \\
{[\mathrm{m} \Omega]}\end{array}$ & $\begin{array}{c}C_{\mathrm{f} 1} \\
{[\mu \mathrm{F}]}\end{array}$ & $\begin{array}{c}C_{\mathrm{f} 2} \\
{[\mu \mathrm{F}]}\end{array}$ & $\begin{array}{c}L_{\mathrm{f}} \\
{[\mathrm{mH}]}\end{array}$ & $n_{\mathrm{p}}$ \\
\hline 80 & 1070.3 & 24349.8 & \multirow{5}{*}{4.3} & \multirow{5}{*}{128.74} & \multirow{5}{*}{242.70} & \multirow{5}{*}{1.2} & \multirow{5}{*}{6} \\
\hline 250 & 1369.9 & 24349.8 & & & & & \\
\hline 750 & 2282.3 & 24349.9 & & & & & \\
\hline 1250 & 2701.5 & 24350.0 & & & & & \\
\hline 8000 & 3112.0 & 24352.9 & & & & & \\
\hline
\end{tabular}

Table VII. Parameters of C-type filter

\begin{tabular}{|c|c|c|c|c|c|c|c|}
\hline \multicolumn{8}{|c|}{$\left(Q_{\mathrm{f}}=-2172.5 \mathrm{Var}\right)$} \\
\hline $\begin{array}{c}R \\
{[\mathrm{~m} \Omega]}\end{array}$ & $\begin{array}{c}Z_{\mathrm{f}(5)} \\
{[\mathrm{m} \Omega]}\end{array}$ & $\begin{array}{c}Z_{\mathrm{f}(1)} \\
{[\mathrm{m} \Omega]}\end{array}$ & $\begin{array}{c}R_{\mathrm{Lf}} \\
{[\mathrm{m} \Omega]}\end{array}$ & $\begin{array}{c}C_{\mathrm{fa}} \\
{[\mu \mathrm{F}]}\end{array}$ & $\begin{array}{c}C_{\mathrm{fb}} \\
{[\mu \mathrm{F}]}\end{array}$ & $\begin{array}{c}\begin{array}{c}L_{\mathrm{f}} \\
{[\mathrm{mH}]}\end{array} \\
\end{array}$ & $n$ \\
\hline 1.25 & 4.7353 & 24.3498 & \multirow{5}{*}{12.7} & \multirow{5}{*}{130.72} & \multirow{5}{*}{2900} & \multirow{5}{*}{3.4} & \multirow{5}{*}{4.85} \\
\hline 5 & 3.5180 & 24.3498 & & & & & \\
\hline 8 & 2.6708 & 24.3498 & & & & & \\
\hline 25 & 1.0487 & 24.3498 & & & & & \\
\hline 2500 & 0.3203 & 24.3498 & & & & & \\
\hline
\end{tabular}

\section{Simulation results}

The capacitor designed for reactive power compensation (in the filters comparative study) is the starting point for the comparative analysis and the reference configuration.

\section{A. Topology No 1 - Capacitors}

The waveforms and spectrum of grid voltage and current before and after the capacitor connection are shown in Fig. 2 and 3. The amplitude of the basic harmonics $\left(5^{\text {th }}, 7^{\text {th }}, 11^{\text {th }}\right.$ and $\left.13^{\text {th }}\right)$ of voltage and current at PCC has increased after the capacitor connection (Fig. 3abcd.). This increase is due to the parallel resonance phenomena caused by the parallel connection between the grid inductance and capacitor. Although the capacitor has amplified the amplitude of basic harmonics it has reduced the amplitude of high harmonics (from the $17^{\text {th }}$ harmonic) of grid current and voltage. The THD has increased from $4.93 \%$ to $6.03 \%$ for the voltage and from $36 \%$ to 116.29 $\%$ for the current. 
The characteristics of system impedance (for different capacitor's reactive power) observed from the input of thyrystor bridge is shown on Fig. 4ab. With the increase of reactive power, the series and parallel resonance are damped and the system is overcompensated.

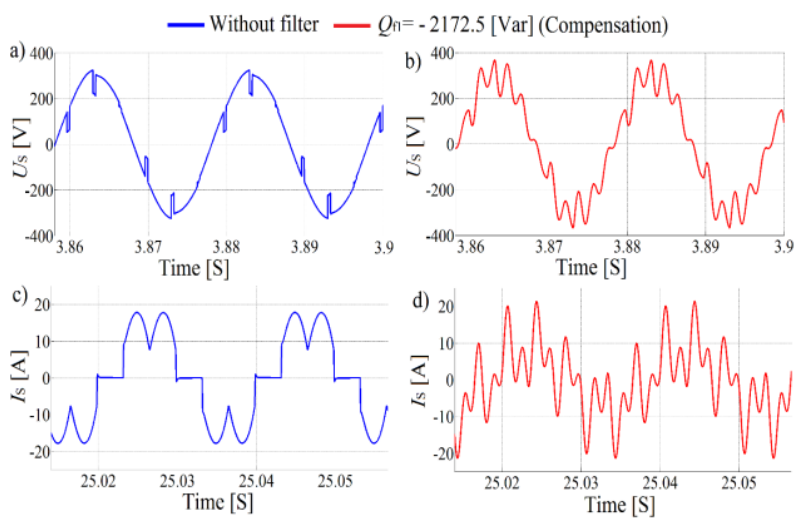

Fig. 2. Grid voltage and current characteristic: before (ac) and after (bd) the capacitor connection

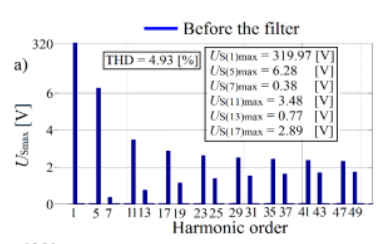

- After the filter $\left(Q_{i}=-2172.5[\mathrm{Var}]\right)$ Compensation

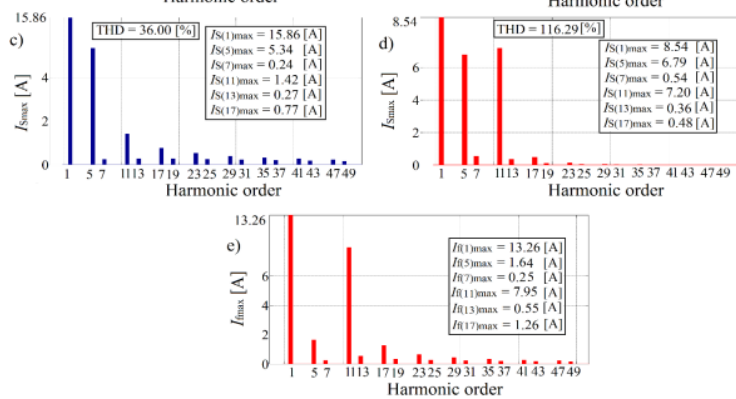

Fig. 3. Influence of capacitor on the spectrum of PCC voltage and current
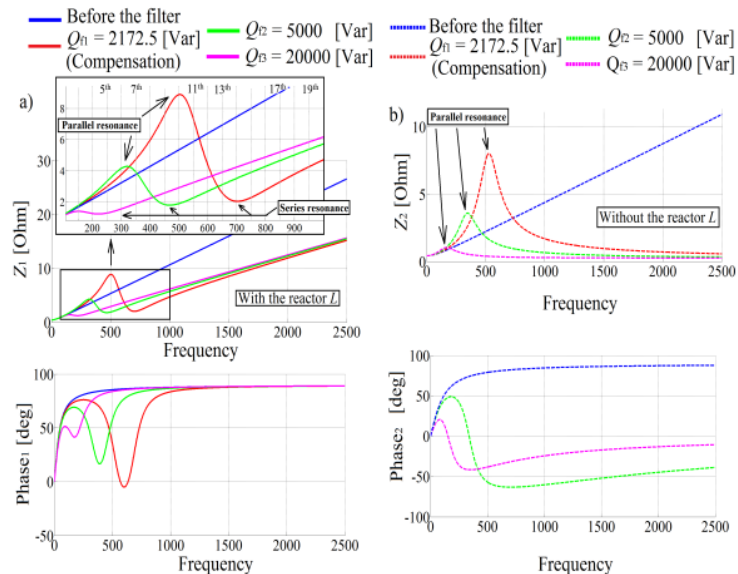

Fig. 4. Characteristics of power system impedance measured at the input of thyrstor bridge: a) with the input reactor $L$, b) without the input reactor $L$

\section{B. Topology No 2 - Single-tuned filter}

The filter is analyzed for different value of detuning frequency. The filter efficiency on the reduction of $5^{\text {th }}$ harmonic of the grid voltage and current has decreased with the decrease of detuning frequency (from $250 \mathrm{~Hz}$ to
$205 \mathrm{~Hz}$ ). The amplitude of the fifth harmonic at the PCC has increased with the decrease of detuning frequency (Fig. 5bd).
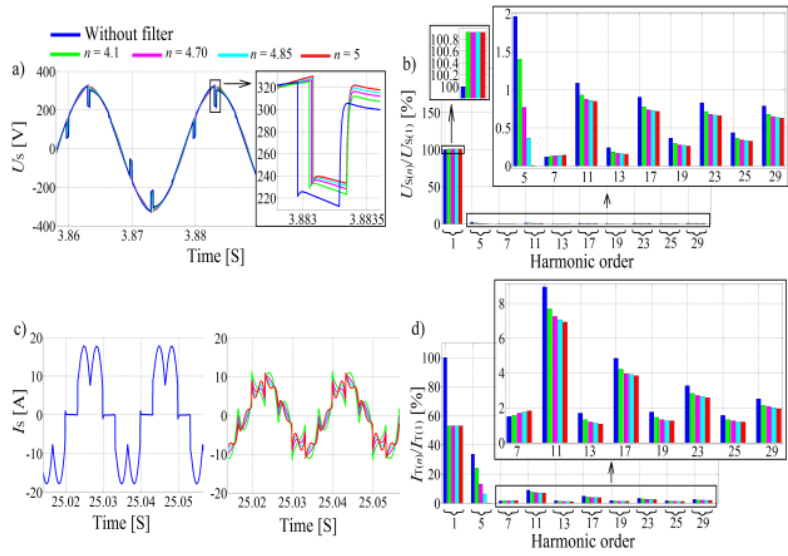

Fig. 5. a) grid voltage, (b) its spectrum; c) grid current, (d) its spectrum

\section{Topology No 3 - Second order damped filter}

The $2^{\text {nd }}$ order filter is analysed by using different value of its damped resistance. At first the power system is tested without filter then the filter branch is connected and at the end the second order filter is analysed (Fig. 7).

With high value of damping resistance $(R=60 \Omega)$, the second-order filter behave as single-tuned filter presenting small value of impedance for the resonance frequency and frequencies near the resonance frequency (e.g. the $5^{\text {th }}$ harmonic frequency). With small value of damping resistance ( $R=3 \Omega$ ), it behaves as first-order filter presenting high value of impedance for the resonance frequency and small value of impedance for the high frequencies (Fig. 6).

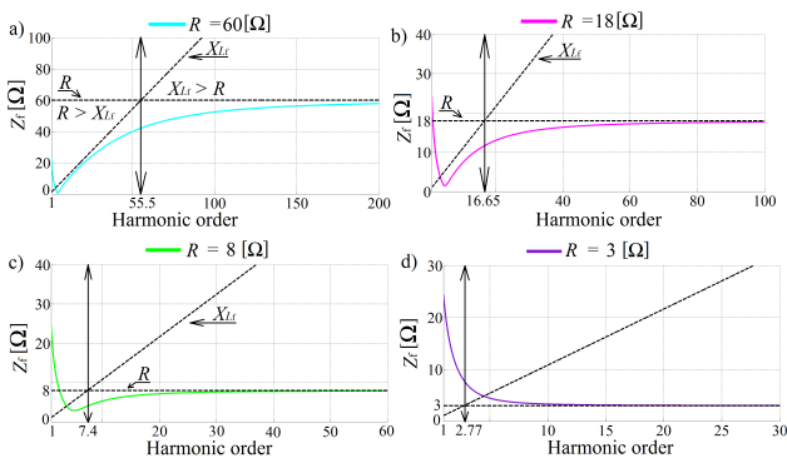

Fig. 6. Filter impedance frequency characteristics: a) $R=60 \Omega$, b) $R=$ $18 \Omega, \mathrm{c}) \mathrm{R}=8 \Omega, \mathrm{d}$ ) ) $\mathrm{R}=3 \Omega$ (see Fig. 1)
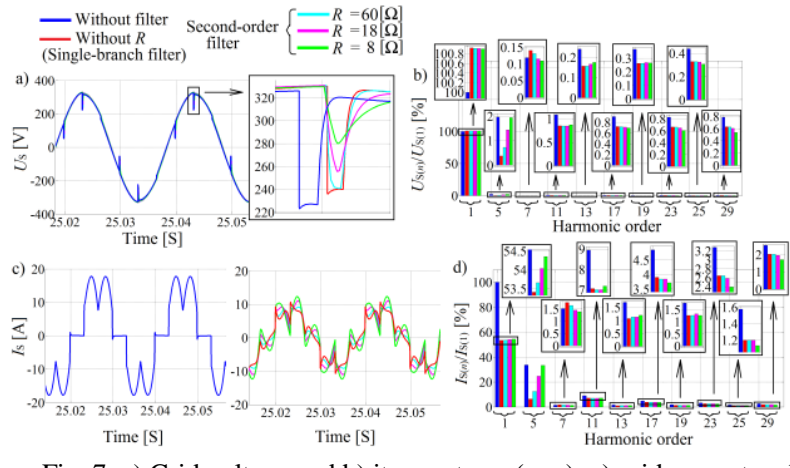

Fig. 7. a) Grid voltage and b) its spectrum (p.u.); c) grid current and d) its spectrum (p.u.) 
The grid voltage and current with their spectrum are presented in Fig.7. It can be observed that the commutation points of grid voltage are lesser and lesser dip when the damping resistance decreases.

\section{Topology No 4 - $3^{\text {rd }}$ order damped filter}

The filter impedance characteristic in function of frequency is presented in Fig. 8. As the damping resistance increases, the filter series and parallel resistance are damped (the filter impedance for the parallel resonance $\left(n_{\mathrm{p}}\right)$ is reduced and increased for the series resonance $(n))$.

With high value of damping resistance (e.g. $8 \Omega$ ), the third order filter is detuned to the frequency of $8^{\text {th }}$ harmonic and its impedance characteristic is similar to the one of single branch filter (Fig. 8). The filter has lost the ability to filter the $5^{\text {th }}$ harmonic, the high harmonics (from the $23^{\text {rd }}$, Fig. 9d) and the commutation points of grid voltage (Fig. 9a). The highest value of damping resistance should be chosen in such a way to maintain a minimum of parallel and series resonance (to maintain the filter efficiency). The smaller is the damped resistance, the better is the reduction of the $5^{\text {th }}$ harmonic amplitude, the high harmonics (in the wide range) and the commutation notches (Fig. 9a) of voltage at the PCC.

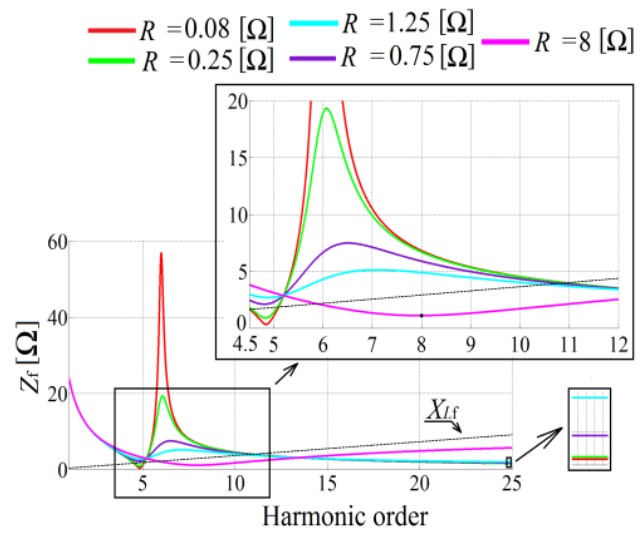

Fig. 8. Filter impedance frequency characteristics

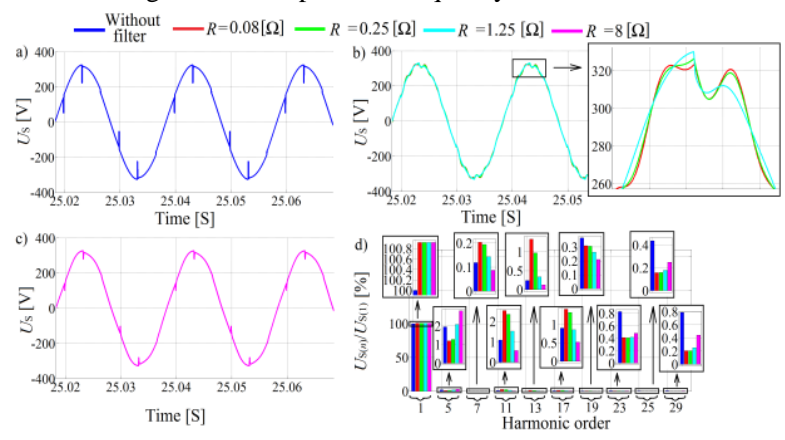

Fig. 9. a) b) c) PCC voltage; d) spectrum (p.u.)

\section{E. Topology No 5 - C-type filter}

The analysis of C-type is focused on its damping resistance and capacitor $\mathrm{C}_{\text {fa. }}$. The damping resistances are chosen in the interval of $0.08 \Omega$ to $8 \Omega$ (Fig. 10) and the value of $\mathrm{C}_{\mathrm{fa}}$ is increased and decreased by $\pm 10 \%$.

For the power losses reduction, the filter must be designed in such a way that less current of fundamental harmonic flows through the damping resistance $R$ (Fig. 1).

The filter impedance frequency characteristics are presented in Fig. 10. For high values of damping resistance filter impedance frequency characteristic is similar to the one of single tuning filter and for the small values, it is similar to the one of first order filter. The higher is the damping resistance value, better is filtered the $5^{\text {th }}$ harmonic and worse is the reduction of the higher harmonics amplitude (Fig. 10a).

The filter impedance of resonance frequencies decreases with the damping resistance increase (Fig. $10 \mathrm{~b})$. For the two identical C-type filter with $R=25 \Omega$, the filter tuned to the $7^{\text {th }}$ harmonic presents lower impedance than the filter tuned to the $5^{\text {th }}$ harmonic (Fig. $10 \mathrm{c})$.

The grid voltage waveform in Fig. 11a presents commutation notches. For small values of damping resistance (e.g. 1.25 $\Omega$ ), the line notches are reduced considerably (Fig. 10b) and amplitude of high harmonics (from 17th to 29th ) as well, although the amplitude of the $5^{\text {th }}, 7^{\text {th }}$ and $11^{\text {th }}$ have been amplified (Fig. 10f and 64f).

For high values of damping resistance (e.g. $8 \Omega, 25 \Omega$ and $2500 \Omega$ ), the filter has difficulties to reduce line notches (Fig. 10cde) and high harmonics amplitude (from $7^{\text {th }}$ to $\left.29^{\text {th }}\right)$ as well. It is then more efficient on the $5^{\text {th }}$ harmonic amplitude reduction (Fig. 11f).

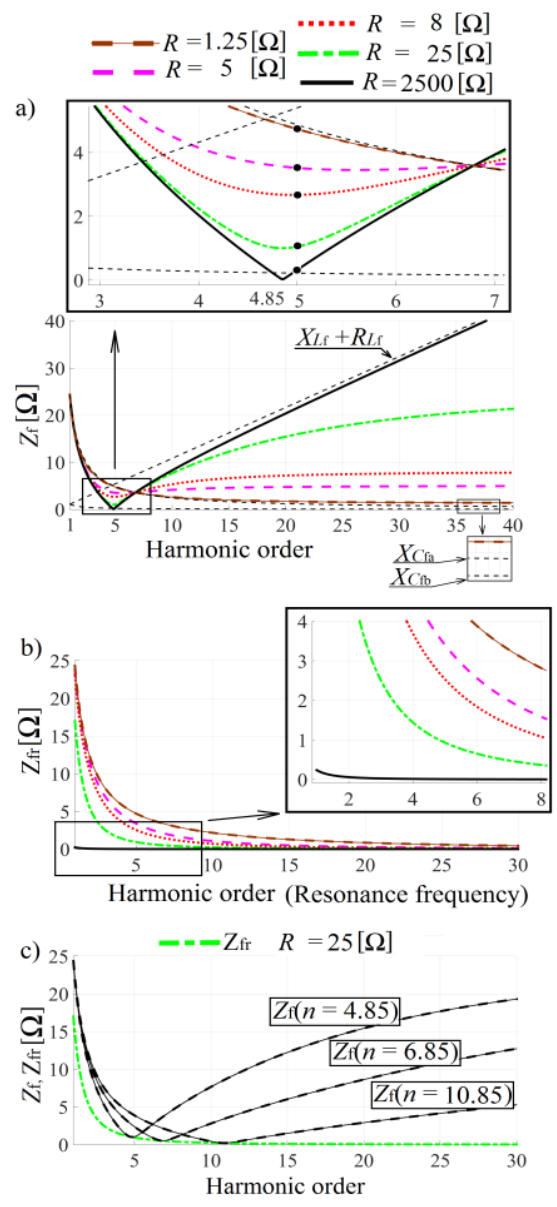

Fig. 10. C-type filter: (a) impedance frequency characteristics; b) filter impedance for resonance frequencies; c) impedance frequency characteristic for different tuned frequencies

The grid voltage parameters are presented in Tab VIII. The THD value has decreased after the filter connection (from $4.93 \%$ to 2.96 ) but with the increase of $R$, it has also increased (to 3.84 ). 
Table VIII. Grid voltage parameters

\begin{tabular}{|c|c|c|c|c|c|c|}
\hline \multicolumn{7}{|c|}{$U_{\mathrm{s} \max }[\mathrm{V}]$} \\
\hline \multirow{2}{*}{\multicolumn{2}{|c|}{$n$}} & \multicolumn{2}{|c|}{ Without filter } & \multicolumn{3}{|c|}{$R=1.25[\Omega]$} \\
\hline & & Ampl. & Phase & Ampl. & \multicolumn{2}{|c|}{ Phase } \\
\hline \multicolumn{2}{|l|}{$1^{\text {st }}$} & 319.97 & 30,7 & 322.76 & \multicolumn{2}{|c|}{29.1} \\
\hline \multicolumn{2}{|l|}{$5^{\text {th }}$} & 6.28 & $-67,4$ & 7.69 & \multicolumn{2}{|c|}{-85.7} \\
\hline \multicolumn{2}{|l|}{$7^{\text {th }}$} & 0.38 & 10.6 & 0.61 & \multicolumn{2}{|c|}{-29.9} \\
\hline \multicolumn{2}{|l|}{$11^{\text {th }}$} & 3.48 & -34.3 & 4.88 & \multicolumn{2}{|c|}{237.0} \\
\hline \multicolumn{2}{|c|}{$13^{\text {th }}$} & 0.77 & -74 & 0.76 & \multicolumn{2}{|c|}{169.2} \\
\hline \multicolumn{2}{|c|}{$17^{\text {th }}$} & 2.89 & -11.1 & 1.80 & \multicolumn{2}{|c|}{219.7} \\
\hline \multicolumn{2}{|c|}{$19^{\text {th }}$} & 1.17 & -60.1 & 0.54 & \multicolumn{2}{|c|}{161.2} \\
\hline \multicolumn{2}{|c|}{$23^{\text {th }}$} & 2.65 & 9.4 & 0.96 & \multicolumn{2}{|c|}{225.5} \\
\hline \multicolumn{2}{|l|}{$25^{\text {th }}$} & 1.4 & -43.4 & 0.41 & & \\
\hline $29^{\text {th }}$ & & & 28.6 & 0.65 & & \\
\hline THD [ & & 4.93 & & & 2.96 & \\
\hline & & & $U_{\mathrm{s} \max }[\mathrm{V}]$ & & & \\
\hline & $\mathrm{R}=8$ & & $\mathrm{R}=2$ & {$[\Omega]$} & $\mathrm{R}=25$ & {$[\Omega]$} \\
\hline$n$ & Ampl. & Phase & Ampl. & Phase & Ampl. & Phase \\
\hline $1^{\text {st }}$ & 322.72 & 28.4 & 322.74 & 29.3 & 322.78 & 29.4 \\
\hline $5^{\text {th }}$ & 5.99 & 255.6 & 3.49 & 249.9 & 1.30 & -64.2 \\
\hline $7^{\text {th }}$ & 0.42 & -8.6 & 0.44 & 14.0 & 0.50 & 16.8 \\
\hline $11^{\text {th }}$ & 2.77 & -78.7 & 2.70 & -56.2 & 2.74 & -50.4 \\
\hline $13^{\text {th }}$ & 0.58 & 239.7 & 0.53 & 265.3 & 0.53 & -86.2 \\
\hline $17^{\text {th }}$ & 2.20 & -75.5 & 2.28 & -45.0 & 2.33 & -38.3 \\
\hline $19^{\text {th }}$ & 0.84 & 231.3 & 0.86 & 263.4 & 0.87 & -88.5 \\
\hline $23^{\text {th }}$ & 1.91 & -75.2 & 2.07 & -36.7 & 2.14 & -28.1 \\
\hline $25^{\text {th }}$ & 0.97 & 226.7 & 1.04 & 267.7 & 1.07 & -82.5 \\
\hline $29^{\text {th }}$ & 1.71 & -76.3 & 1.96 & -29.8 & 2.03 & -19.2 \\
\hline $\begin{array}{l}\text { THD } \\
{[\%]}\end{array}$ & 2.8 & & & & & \\
\hline
\end{tabular}

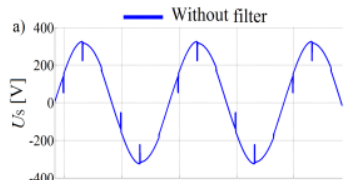

$\begin{array}{lllll}-409_{25.02} & 25.03 & 25.04 & 25.05 & 25.06\end{array}$ Time $[\mathrm{S}]$

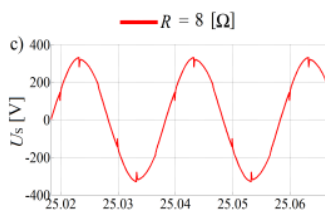

Time $[\mathrm{S}]$

$$
-R=2500[\Omega]
$$
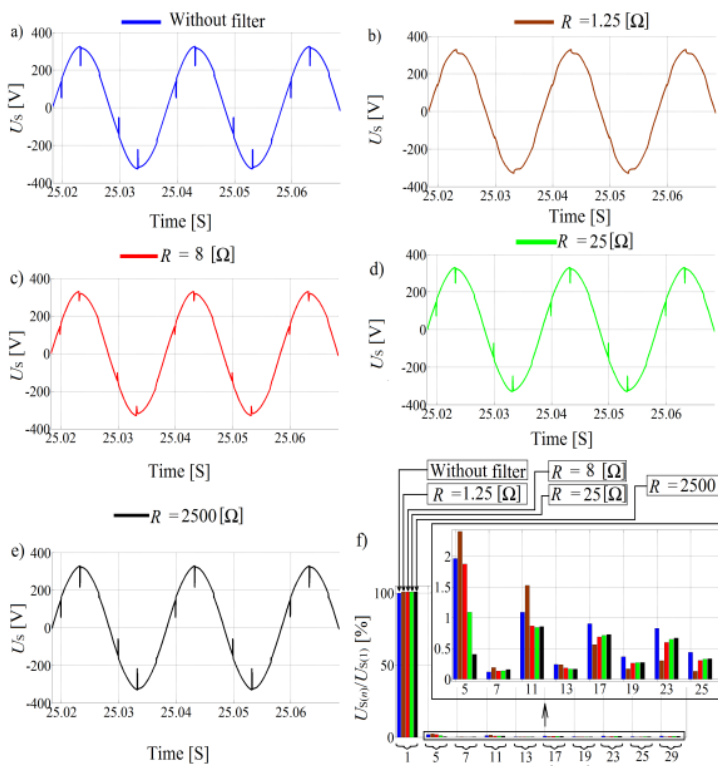
Time $[\mathrm{S}]$
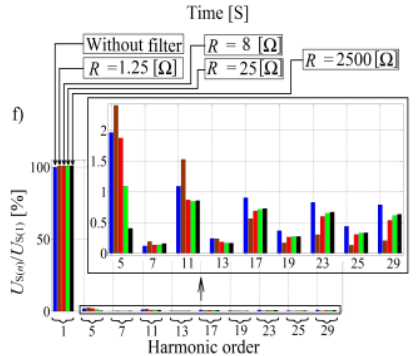

Fig. 11. a) b) c) e) PCC voltage, f) spectrum (p.u.)

The increase and decrease of C-type filter capacitor $\left(C_{\mathrm{fa}}\right)$ by $\pm 10 \%$ of its nominal value has caused the filter detuning of filter (Fig. 12). In the case of $C_{\mathrm{fa}(-10)}$ the $5^{\text {th }}$ harmonic impedance is on the capacity side of the characteristic.

The increase of filter capacitor by $10 \%$ has caused the overcompensation of system (Fig. 13b). Its decrease has caused, the increase of the THD of grid voltage and current and increase of power losses at the PCC (Fig. $13 \mathrm{cb})$.

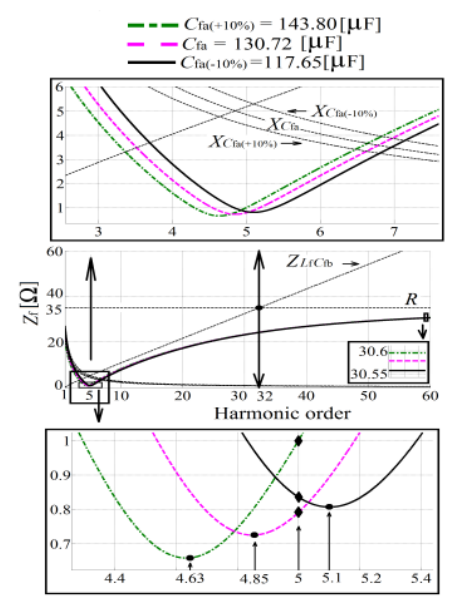

Fig. 12. Impedance frequency characteristic for different of filter capacitor $C_{\mathrm{fa}}$

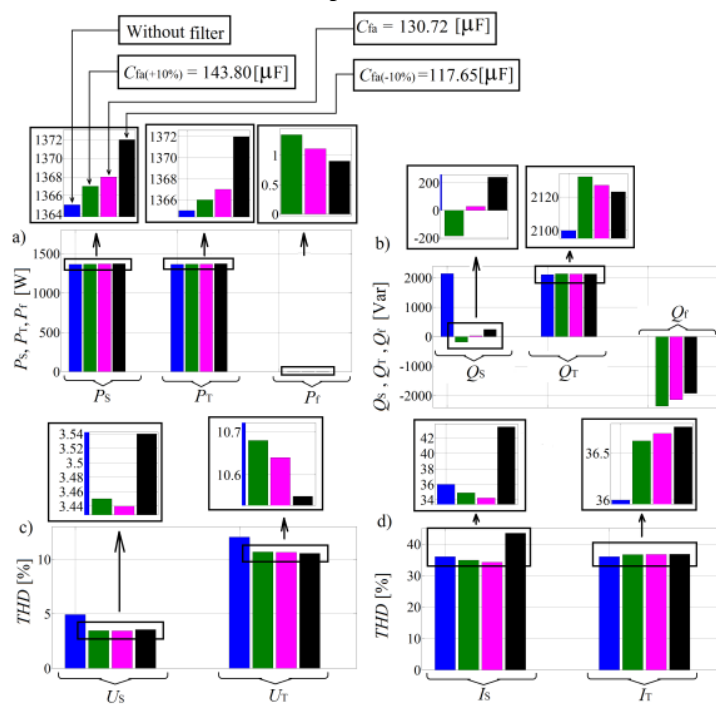

Fig. 13. a) active power measured at the $\operatorname{PCC}\left(P_{\mathrm{S}}\right)$, filter terminals $\left(P_{\mathrm{f}}\right)$ and input of rectifier $\left(P_{\mathrm{T}}\right)$; b) reactive power measured at the PCC $\left(Q_{\mathrm{S}}\right)$, filter terminals $\left(Q_{\mathrm{f}}\right)$ and input of rectifier $\left.\left(Q_{\mathrm{T}}\right) ; \mathrm{c}\right)$ THD of PCC voltage $\left(U_{\mathrm{S}}\right)$ and voltage at the input of rectifier $\left(U_{\mathrm{T}}\right)$; d $)$ THD of PCC current $\left(I_{\mathrm{S}}\right)$ and current at the input of rectifier $\left(I_{\mathrm{T}}\right)$

\section{Experimental results}

The laboratory model is the same as the simulated model but the difference is only on the parameters. The chosen topology for the laboratory experimental is the single-tuned filter (parameters in Tab IX).

Table IX. Parameters of single-tuned filter

\begin{tabular}{|c|c|c|c|c|c|}
\hline$n$ & $\begin{array}{c}C_{\mathrm{f}} \\
{[\mu \mathrm{F}]}\end{array}$ & $\begin{array}{c}L_{\mathrm{f}} \\
{[\mu \mathrm{H}]}\end{array}$ & $\begin{array}{c}Z_{\mathrm{f}(5)} \\
{[\Omega]}\end{array}$ & $\begin{array}{c}Z_{\mathrm{f}(1)} \\
{[\Omega]}\end{array}$ & $\begin{array}{c}Q_{\mathrm{f}} \\
{[\mathrm{KVar}]}\end{array}$ \\
\hline 4.91 & 1700 & 252 & 0.778 & 1.99 & -27.871 \\
\hline
\end{tabular}

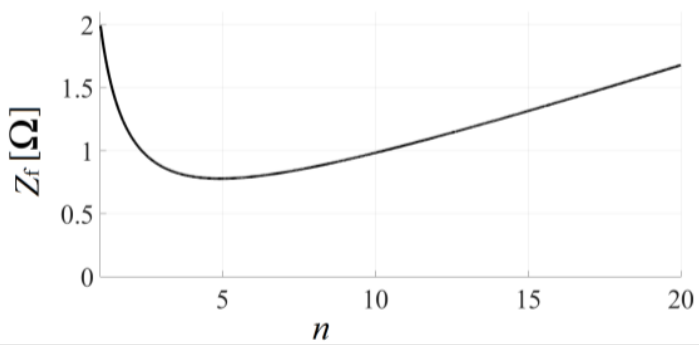

Fig. 14. Impedance frequency characteristic of single-branch filter 


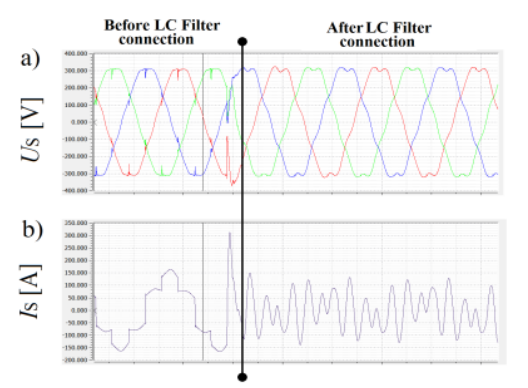

Fig. 15. Grid voltage (a) and current (b)

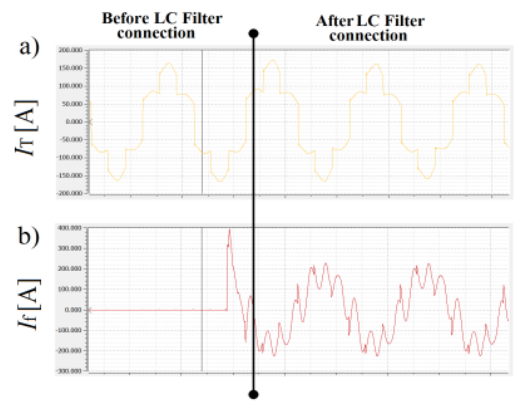

Fig. 16. a) Current at the input of thyrystor bridge $\left(\mathrm{I}_{\mathrm{T}}\right)$, filter current $\left(\mathrm{I}_{\mathrm{f}}\right)$

Table X. Measured parameters

\begin{tabular}{|c|c|c|c|c|}
\hline \multirow{2}{*}{$\mathrm{n}$} & \multicolumn{2}{|c|}{$U_{\mathrm{S}}[\mathrm{V}]$} & \multicolumn{2}{c|}{$I_{\mathrm{S}}[\mathrm{A}]$} \\
\cline { 2 - 5 } & $\mathrm{Ampl}$ & {$\left[^{\circ}\right]$} & $\mathrm{Ampl}$ & $\left.{ }^{\circ}\right]$ \\
\hline $1^{\text {st }}$ & 227.38 & -89.29 & 18.68 & -32.12 \\
\hline $3^{\text {rd }}$ & 3.77 & 53.88 & 1.91 & -114.61 \\
\hline $5^{\text {th }}$ & 8.64 & 82.21 & 42.37 & -174.11 \\
\hline $7^{\text {th }}$ & 10.93 & -116.56 & 49.68 & -19.30 \\
\hline $9^{\text {th }}$ & 2.23 & -102.75 & 1.89 & 54.78 \\
\hline $11^{\text {th }}$ & 1.15 & 178.92 & 6.78 & -25.97 \\
\hline $13^{\text {th }}$ & 0.63 & 28.27 & 3.96 & -126.15 \\
\hline
\end{tabular}

\begin{tabular}{|c|c|c|c|c|}
\hline \multirow{2}{*}{$\mathrm{n}$} & \multicolumn{2}{|c|}{$I_{\mathrm{f}}[\mathrm{A}]$} & \multicolumn{2}{c|}{$I_{\mathrm{T}}[\mathrm{A}]$} \\
\cline { 2 - 5 } & Ampl & {$\left[^{\circ}\right]$} & Ampl & {$\left[^{\circ}\right]$} \\
\hline $1^{\text {st }}$ & 123.15 & 1.03 & 108.04 & -173.52 \\
\hline $3^{\text {rd }}$ & 0.86 & 155.63 & 2.09 & -90.97 \\
\hline $5^{\text {th }}$ & 23.34 & 169.16 & 21.15 & -155.31 \\
\hline $7^{\text {th }}$ & 46.61 & -28.71 & 8.46 & 44.35 \\
\hline $9^{\text {th }}$ & 2.65 & 8.55 & 1.90 & 142.74 \\
\hline $11^{\text {th }}$ & 9.54 & -71.33 & 6.80 & 63.45 \\
\hline $13^{\text {th }}$ & 1.75 & 104.06 & 5.27 & -111.42 \\
\hline
\end{tabular}

Table XI. Measured powers

\begin{tabular}{|c|c|c|}
\cline { 2 - 3 } \multicolumn{1}{c|}{} & Before the filter & After the filter \\
\hline Grid & $P_{\mathrm{S}}=2.5224[\mathrm{~kW}]$ & $P_{\mathrm{S}}=2.3028[\mathrm{~kW}]$ \\
(PCC) & $Q_{\mathrm{S}}=23.295[\mathrm{KVar}]$ & $Q_{\mathrm{S}}=-3.5691[\mathrm{KVar}]$ \\
\hline $\begin{array}{c}\text { Input of } \\
\text { thyristor } \\
\text { bridge }\end{array}$ & $P_{\mathrm{T}}=2.5224[\mathrm{~kW}]$ & $P_{\mathrm{T}}=2.4698[\mathrm{KW}]$ \\
\hline Filter & $Q_{\mathrm{T}}=23.295[\mathrm{KVar}]$ & $Q_{\mathrm{T}}=24.442[\mathrm{KVar}]$ \\
\hline & - & $P_{\mathrm{F}}=0.15639[\mathrm{KW}]$ \\
& - & $Q_{\mathrm{F}}=-28.001[\mathrm{KVar}]$ \\
\hline
\end{tabular}

The waveforms of obtained after the laboratory experiment are presented in Fig.15 and Fig. 16.

According to Fig. 14 the design of filter in the lab was successfully done. But according the results presented in Tab X, the amplitude of $5^{\text {th }}$ harmonic has not been reduced but amplified due to the resonance phenomena between the filter capacitor and the grid inductor.

\section{Conclusion}

In table XII the topologies are compared on the basis of the following criteria: the amplitude of $5^{\text {th }}$ harmonic of grid voltage, the grid voltage THD and the filter power losses. The parameters were chosen for the minimum values of damping resistance $\left(\mathrm{R}_{\mathrm{min}}\right)$. The reactor quality factor is not the same for each topology $\left(R_{\mathrm{Lf}}\right)$

According to the simulation result, the single-tuned filter is the best on the reduction of $5^{\text {th }}$ harmonic. The $\mathrm{C}$ type filter is the best on the improving of grid voltage waveform. Less power losses are generated by the $3^{\text {rd }}$ order filter.

\begin{tabular}{|c|c|c|c|c|c|}
\hline & \multicolumn{5}{|c|}{$\begin{array}{l}\text { Table XII. Comparison of different filter } \\
\text { configuration }\end{array}$} \\
\hline & \multicolumn{5}{|c|}{$Q_{\mathrm{f}}=-2172.5 \operatorname{Var}, \theta=57^{\circ}, \omega=1500 \mathrm{rpm}$} \\
\hline & Capacitor & $\begin{array}{l}\text { Single- } \\
\text { tuned }\end{array}$ & $\begin{array}{l}\text { Second } \\
\text { order }\end{array}$ & $\begin{array}{l}3^{\text {rd }} \\
\text { order }\end{array}$ & C-type \\
\hline$\overline{U_{\mathrm{S}(5)}[\mathrm{V}]}$ & 5.60 & 0.84 & 4.4 & 2.71 & 2.59 \\
\hline$T H D_{U_{\mathrm{s}}}[\mathrm{V}]$ & 4.35 & 3.82 & 2.92 & 3.45 & 1.88 \\
\hline$\Delta P_{\mathrm{f}(1)}[\mathrm{W}]$ & 21.97 & 6.557 & 18.42 & 0.41 & 1.16 \\
\hline$R_{\min }[\Omega]$ & 0.25 & 0.0749 & 8 & 0.08 & 1.25 \\
\hline$R_{L \mathrm{f}}$ & - & - & 74.9 & 4.3 & 12.7 \\
\hline
\end{tabular}

\section{Acknowledgment}

This work was supported by the National Fund for Environmental Protection and Water Management and the National Centre for Research and Development under project No. GEKON1/02/213877/31/2015.

\section{REFERENCES}

[1] Arrillaga J., Bradley D.A., Bodger P.S.: Power System Harmonic, John Wiley \& Sons, cop. 1985.

[2] Abu-Rubu H., Iqbal A., Guzinski J.: High Performance Control of AC Drives with MATLAB/SIMULINK Models, John Wiley \& Sons, 2012.

[3] Czarnecki. L.S., ginn. H. L.: The Effect of the Design Method on Efficiency of Resonant Harmonic Filters, IEEE Transactions on power Delivery, Vol.20, No. 1, 2005, PP. 286-291.

[4] M. Rusli., M. Ihsan., D. Setiawan.: A Single Tuned Harmonic Filter Design as Total Hamonic Distortion (THD) Compensator, CIRED Interbational Conference on Electrical Distribution, Lyon 2015.

[5] Hanzelka Z.: Selected aspects of the design of passive harmonic filters (in Polish), Automatyka, Elektryka, Zakłócenia, Infotech conference. Jurata, 23-26 June 2010.

[6] Klempka R.: Improving the power quality supply with the use of genetic algorithms (in Polish), AGH. Krakow 2013.

[7] Azebaze, M.C.S., Hanzelka Z.: Different approaches for designing the passive power filters, IEEE International School on Nonsinusoidal Currents and Compensation conference-seminar, 15-18 June 2015, Łagów, Poland

[8] Azebaze, M.C.S., Hanzelka Z.: Application of C-type filter to DC adjustable speed drive, accepted in IEEE International conference Modern Electric Power Systems, July 6-9, 2015, Wroclaw, Poland.

[9] Liserre M., Aquila A.D., Blaabjerg F.: Stability Improvement of an LCL-filter Based Three-phase Active Rectifier, IEEE Power Electronics Specialists Conference, vol. 3, 2002, pp. 1195 - 1201.

[10] Sik.Cho Y., Cha H.: Single-tuned Passive Harmonic Filter Design Considering Variances of Tuning and Quality Factor, Journal of International Council on Electrical Engineering, vol. 1, no. 1, 2011, pp. 7-13. 